\title{
RANTES Modulates the Release of Glutamate in Human Neocortex
}

\author{
Veronica Musante, ${ }^{1}$ Fabio Longordo, ${ }^{3}$ Elisa Neri, ${ }^{1}$ Marco Pedrazzi, ${ }^{2}$ Fotios Kalfas, ${ }^{4}$ Paolo Severi, ${ }^{4}$ Maurizio Raiteri,,${ }^{1,5}$ \\ and Anna Pittaluga ${ }^{1,5}$ \\ ${ }^{1}$ Section of Pharmacology and Toxicology and ${ }^{2}$ Section of Biochemistry, Department of Experimental Medicine, University of Genoa, 16148 Genoa, Italy, \\ ${ }^{3}$ Biozentrum, University of Basel, CH 4056 Basel, Switzerland, ${ }^{4}$ Division of Neurosurgery, Galliera Hospital, 16128 Genoa, Italy, and ${ }^{5}$ Center of Excellence \\ for Biomedical Research, University of Genoa, 16132 Genoa, Italy
}

The effects of the recombinant chemokine human RANTES (hRANTES) on the release of glutamate from human neocortex glutamatergic nerve endings were investigated. hRANTES facilitated the spontaneous release of $d\left[{ }^{3} \mathrm{H}\right] \mathrm{D}$-aspartate $\left(\left[{ }^{3} \mathrm{H}\right]_{\mathrm{D}} \mathrm{DSP}\right)$ by binding Pertussis toxin-sensitive G-protein-coupled receptors (GPCRs), whose activation caused $\mathrm{Ca}^{2+}$ mobilization from inositol trisphosphate-sensitive stores and cytosolic tyrosine kinase-mediated phosphorylations. Facilitation of release switched to inhibition when the effects of hRANTES on the $12 \mathrm{~mm} \mathrm{~K}^{+}$-evoked $\left[{ }^{3} \mathrm{H}\right.$ ] -ASP exocytosis were studied. Inhibition of exocytosis relied on activation of Pertussis toxin-sensitive GPCRs negatively coupled to adenylyl cyclase. Both hRANTES effects were prevented by met-RANTES, an antagonist at the chemokine receptors (CCRs) of the CCR1, CCR3, and CCR5 subtypes. Interestingly, human neocortex glutamatergic nerve endings seem to possess all three receptor subtypes. Blockade of CCR1 and CCR5 by antibodies against the extracellular domain of CCRs prevented both the hRANTES effect on $\left[{ }^{3} \mathrm{H}\right] \mathrm{D}$-ASP release, whereas blockade of CCR3 prevented inhibition, but not facilitation, of release. The effects of RANTES on the spontaneous and the evoked release of $\left[{ }^{3} \mathrm{H}\right] \mathrm{D}-\mathrm{ASP}$ were also observed in experiments with mouse cortical synaptosomes, which may therefore represent an appropriate animal model to study RANTES-induced effects on neurotransmission. It is concluded that glutamate transmission can be modulated in opposite directions by RANTES acting at distinct CCR receptor subtypes coupled to different transduction pathways, consistent with the multiple and sometimes contrasting effects of the chemokine.

Key words: human RANTES; human neocortex; basal glutamate release; evoked glutamate release; chemokine receptors; cytokine

\section{Introduction}

Chemokines are small proteins widely expressed in human body, including the brain. First investigated for their involvement in central neuroinflammation, they have more recently attracted attention as potential neurotransmitters/neuromodulators (Bajetto et al., 2002; Cho and Miller, 2002; Cartier et al., 2005).

Among the chemokines so far identified, the compound termed "regulated upon activation normal T cell expressed and secreted" (RANTES) seems particularly relevant to CNS diseases secondary to viral infections like AIDS-related dementia (van der Meer et al., 2000; Alvarez Losada et al., 2002; Bajetto et al., 2002; Cartier et al., 2005), or involving neuroinflammatory processes like multiple sclerosis (Sørensen et al., 1999; Bajetto et al., 2002).

Received July 10, 2008; revised Sept. 22, 2008; accepted Sept. 24, 2008.

This work was supported by grants from Istituto Superiore di Sanità (Quinto Programma Nazionale di Ricerca sull'AIDS: Progetto "Patologia, Clinica e Terapia dell'AIDS"), from Fondazione Italiana Sclerosi Multipla (cod. 2005/ R/17), and from Ministero dell'Istruzione, dell'Università e della Ricerca Scientifica Project numbers 2004052809_004 (A.P.) and 2003053993 (M.R.). We thank the Department of Immunology and Oncology, the National Institute for Biological Standards and Control (NIBSC) Centralised Facility for AIDS reagents (European Union Programme EVA, contract QLKZ-CT-1999-00609), and the United Kingdom Medical Research Council (Hertfordshire, UK) for kindly supplying us with anti-CCR5 antibody and with human recombinant RANTES (NIBSC 92/ 520). We thank Maura Agate and Silvia E. Smith for careful editorial assistance.

Correspondence should be addressed to Anna Pittaluga, Department of Experimental Medicine, Section of Pharmacology and Toxicology, Viale Cembrano, 16148 Genoa, Italy. E-mail: pittalug@pharmatox.unige.it.

DOI:10.1523/JNEUROSCI.3212-08.2008

Copyright $\odot 2008$ Society for Neuroscience $\quad 0270-6474 / 08 / 2812231-10 \$ 15.00 / 0$
RANTES is a 68 amino acid protein, able to bind as a promiscuous ligand to different G-protein-coupled receptors (GPCRs) that are constitutively expressed in the CNS of normal individuals (Klein et al., 1999; Bajetto et al., 2002; Cartier et al., 2005; Ubogu et al., 2006) and to the recently identified G-proteincoupled receptor 75 (Ignatov et al., 2006). RANTES was found to control the mobilization of cytosolic $\mathrm{Ca}^{2+}$ and the production of different second messengers in cultured neurons (Meucci et al., 1998; Boutet et al., 2001; Oh et al., 2001, 2002; Gillard et al., 2002), astrocytes (Klein et al., 1999), and microglia (Hegg et al., 2000).

Despite the expression of chemokine receptors (CCRs), RANTES can hardly be detected in cerebral spinal fluid of normal individuals; however, its levels can increase dramatically when HIV-1 infection occurs (Kelder et al., 1998; Kolb et al., 1999; McManus et al., 2000) or during the initiation and the relapsing phases of multiple sclerosis (Ransohoff et al., 1993; Karpus and Ransohoff, 1998; Sørensen et al., 1999; Iarlori et al., 2000).

Considering that excitotoxicity caused by excessive glutamate is believed to play major roles in neurodegenerative conditions, we investigated the effects of hRANTES on the release of glutamate from human neocortex nerve endings, which were isolated from tissue samples removed during neurosurgical procedures to reach deeply located tumors. Our results highlight a dual role of RANTES in glutamate transmission: the chemokine can potenti- 
ate the basal release of glutamate, but it can inhibit the depolarization-evoked release of the excitatory amino acid. Pertussis toxin (PTx)-sensitive CCRs coupled to different intraterminal transduction mechanisms account for the opposite effects.

In an attempt to investigate the effects of RANTES in a preparation devoid of potential confounding factors (i.e., production of proinflammatory agents) possibly present in the human brain biopsies, we studied the effects of recombinant mouse RANTES (mRANTES) on the release of $\left[{ }^{3} \mathrm{H}\right] \mathrm{D}$-ASP from mouse cortical synaptosomes. As in human nerve endings, RANTES facilitated the spontaneous release but inhibited the $\mathrm{K}^{+}$-evoked release of excitatory neurotransmission.

\section{Materials and Methods}

Human brain tissue samples. Samples of human cerebral cortex were obtained from informed and consenting patients undergoing neurosurgery to reach deeply seated tumors. The samples represented parts of frontal, parietal, and temporal lobes obtained from 14 women and 21 men (ages 21-70 years). Patients were treated with phenytoin $(10 \mathrm{mg} / \mathrm{kg}$ ) $24 \mathrm{~h}$ before neurosurgery. After a premedication with midazolam (2 $\mathrm{mg} / \mathrm{kg})$, anesthesia was induced with propofol ( $2 \mathrm{mg} / \mathrm{kg})$, cisatracurium $(10-14 \mathrm{mg})$, and fentanyl $(0.1 \mathrm{mg})$ and maintained with propofol (5 $\mu \mathrm{g} / \mathrm{kg} / \mathrm{h})$ and remifentanil $(0.005-0.008 \mu \mathrm{g} / \mathrm{min})$ during neurosurgery. Immediately after removal, the tissues were placed in a physiological salt solution at $2-4^{\circ} \mathrm{C}$, and purified synaptosomal fractions or slices were prepared within $30 \mathrm{~min}$. The experimental procedures were approved by the Ethical Committee of the University of Genoa.

Mouse brain tissue samples. Adult male mice (Swiss; 20-25 g) were housed at constant temperature $\left(22 \pm 1^{\circ} \mathrm{C}\right)$ and relative humidity $(50 \%)$ under a regular light/dark schedule (light 7.00 A.M. to 7.00 P.M.). Food and water were freely available. The animals were killed by decapitation, and the cerebral cortices were rapidly removed. The experimental procedures were approved by the department's Ethical Committee, in accordance with the European legislation (European Communities Council directive of 24 November 1986, 86/609/EEC). Experiments were performed in accordance with the Guidelines for Animal Care and Use of the National Institutes of Health.

Preparation of synaptosomes. Purified synaptosomes were prepared according to Dunkley et al. (1986), with some modifications. Briefly, the tissue was homogenized in $10 \mathrm{vol}$ of $0.32 \mathrm{~m}$ sucrose, buffered to $\mathrm{pH} 7.4$ with Tris (final concentration, $0.01 \mathrm{M}$ ) using a glass/Teflon tissue grinder (clearance $0.25 \mathrm{~mm}$ ); the homogenate was centrifuged at $1000 \times \mathrm{g}$ for 5 min to remove nuclei and debris, and the supernatant was gently stratified on a discontinuous Percoll gradient $(6,10$ and 20\% v/v in Trisbuffered sucrose) and centrifuged at 33,500 $\times g$ for $5 \mathrm{~min}$. The layer between 10 and $20 \%$ Percoll (synaptosomal fraction) was subsequently collected and washed by centrifugation. In a set of experiments, the tissue was homogenized in buffered sucrose containing $1 \mathrm{~mm}$ 1,2-bis-(2aminophenoxy) ethane- $N, N, N^{\prime}, N^{\prime}$, tetra-acetic acid (BAPTA) or $5 \mathrm{~nm}$ $\mathrm{PTx}$, to entrap these agents into subsequently isolated synaptosomes (Raiteri et al., 2000). The synaptosomal pellets were always resuspended in a physiological solution (standard medium) with the following composition (in mM): $125 \mathrm{NaCl}, 3 \mathrm{KCl}, 1.2 \mathrm{MgSO}_{4}, 1.2 \mathrm{CaCl}_{2}, 1 \mathrm{NaH}_{2} \mathrm{PO}_{4}, 22$ $\mathrm{NaHCO}_{3}, 10$ glucose (aeration with $95 \% \mathrm{O}_{2}$ and $5 \% \mathrm{CO}_{2}$ ); pH 7.2-7.4. Synaptosomal protein contents were determined according to Bradford (1976).

Preparation of slices. Slices of human brain samples ( $0.4 \mathrm{~mm}$ thick) were prepared from the parietotemporal or from the frontal cortex (either left or right) using a McIlwain tissue chopper (Mickle Laboratory Engineering) and then placed in a standard medium at $2-4^{\circ} \mathrm{C}$ and rinsed by changing the physiological solution every $20 \mathrm{~min}$.

Experiments of release from synaptosomes. Synaptosomes were labeled with $\left[{ }^{3} \mathrm{H}\right]_{\mathrm{D}}$-ASP; final concentration $60 \mathrm{nM}$ ), at $37^{\circ} \mathrm{C}$, for $15 \mathrm{~min}$, in a rotary water bath and in an atmosphere of $95 \% \mathrm{O}_{2}$ and $5 \% \mathrm{CO}_{2}$. When indicated, synaptosomes were incubated for $85 \mathrm{~min}$ in presence of the following antibodies: rabbit anti-CCR1 (1:1000), mouse anti-CCR3 (1: 1000), mouse anti-CCR5 (1:1000), mouse anti- $\beta$-tubulin 3 (1:1000); rabbit anti- GluR1 (1:1000) or rabbit anti-mGluR5 (1:1000); in these experiments the radioactive tracer was added at $t=70 \mathrm{~min}$ of incubation. After the labeling period, identical portions of the synaptosomal suspensions were layered on microporous filters at the bottom of parallel chambers in a Superfusion System (Raiteri and Raiteri, 2000) (Ugo Basile) maintained at $37^{\circ} \mathrm{C}$. Synaptosomes were superfused at $0.5 \mathrm{ml} / \mathrm{min}$ with standard physiological solution aerated with $95 \% \mathrm{O}_{2}$ and $5 \% \mathrm{CO}_{2}$, at $37^{\circ} \mathrm{C}$.

During examination of the effect of RANTES on the spontaneous release of $\left[{ }^{3} \mathrm{H}\right] \mathrm{D}$-ASP, synaptosomes were first equilibrated during 36 min of superfusion, and then eight consecutive 1 min fractions (termed b1 to b8) were collected. hRANTES or mRANTES, as indicated, and met-RANTES were introduced at the end of the first fraction collected (b1; $t=39 \mathrm{~min}$ ); enzyme inhibitors or the glutamate transporter blocker DL-threo-ß-benzyloxyaspartic acid (DL-TBOA) were present starting from $8 \mathrm{~min}$ before the RANTES stimulus. In a set of experiments performed to evaluate the $\mathrm{Ca}^{2+}$-dependency of the induced $\left[{ }^{3} \mathrm{H}\right] \mathrm{D}$-ASP release, the superfusion medium was replaced, starting from $t=20 \mathrm{~min}$, with a medium containing $0.1 \mathrm{~mm} \mathrm{Ca}^{2+}$ and $500 \mu \mathrm{M}$ EGTA. When studying the effect of RANTES (hRANTES or mRANTES, as indicated) on the $\left[{ }^{3} \mathrm{H}\right] \mathrm{D}$-ASP release evoked by high $\mathrm{K}^{+}$or by the presence of forskolin, synaptosomes were transiently ( $90 \mathrm{~s}$ ) exposed, at $t=39 \mathrm{~min}$, to $12 \mathrm{~mm} \mathrm{KCl}$-containing medium ( $\mathrm{NaCl}$ substituting for an equimolar concentration of $\mathrm{KCl}$ ), or to the adenylyl cyclase activator. Fractions were collected according to the following scheme: two 3-min fractions (basal release), one before $(t=36-39 \mathrm{~min})$ and one after $(t=45-48 \mathrm{~min})$ a 6-min fraction ( $t=39-45 \mathrm{~min}$; evoked release). In these experiments, synaptosomes were exposed to RANTES and to met-RANTES concomitantly with the depolarizing stimulus. Enzyme inhibitors or the cAMP analog 8 -Br-cAMP were added 8 min before RANTES and maintained throughout the superfusion. In a set of experiments, synaptosomes were exposed to RANTES prior (from $t=30 \mathrm{~min}$ to $t=38 \mathrm{~min}$ ) or after (from $t=40 \mathrm{~min}$ to $t=48 \mathrm{~min}$ ) the $\mathrm{K}^{+}$stimulus. Superfusion was always performed with media containing dialyzed $0.1 \%$ Polypep to avoid sticking of peptides to glass walls and tubing. Fractions collected and superfused synaptosomes were counted for radioactivity. The amount of radioactivity released into each superfusate fraction was expressed as a percentage of the total synaptosomal tritium content at the start of the fraction collected (fractional efflux). When expressed as "\% of b1" (see Fig. 1), the RANTES-induced effect was evaluated as the ratio between the percentage of tritium released into each fraction after the first (b2 to b8) and that in the first (b1) fraction collected. When expressed as "\% induced overflow," drug effects were estimated by subtracting the neurotransmitter content into the fractions corresponding to the basal release from those corresponding to the evoked release.

Experiments of release from slices. Slices were labeled with $90 \mathrm{~nm}\left[{ }^{3} \mathrm{H}\right]_{\mathrm{D}}-$ ASP $\left(20 \mathrm{~min}\right.$ at $\left.37^{\circ} \mathrm{C}\right)$ in standard medium in an atmosphere of $95 \% \mathrm{O}_{2}$ and $5 \% \mathrm{CO}_{2}$. After washing with tracer-free medium, slices were transferred to parallel superfusion chambers (one slice/chamber) and superfused $\left(1 \mathrm{ml} / \mathrm{min}\right.$ at $\left.37^{\circ} \mathrm{C}\right)$. After $60 \mathrm{~min}$ of superfusion to equilibrate the system, six 5-min samples were collected. Slices were exposed to hRANTES or met-RANTES in absence or in presence of the depolarizing stimuli ( 30 or $50 \mathrm{~mm} \mathrm{KCl}$ ) for $5 \mathrm{~min}$, starting from $t=70 \mathrm{~min}$ of superfusion. Samples collected and solubilized slices (Soluene; Canberra Packard) were counted for radioactivity. The amount of radioactivity released into each superfusate fraction was expressed as fractional efflux (see above). Drug effects were expressed as "\% induced overflow" and were estimated by subtracting the neurotransmitter content into the second and the fifth fractions collected from that in the third and in the fourth fractions collected.

Isolation of detergent-soluble fractions from crude synaptosomes. Synaptosomes were washed twice with standard medium and then collected by centrifugation $\left(14000 \times \mathrm{g}, 15 \mathrm{~min}\right.$ at $\left.4^{\circ} \mathrm{C}\right)$. The pellet was lysed in ice-cold Tris solution $(20 \mathrm{~mm}$ Tris/ $\mathrm{HCl}, 10 \mathrm{~mm} \mathrm{NaCl}$, protease inhibitor cocktail, $\mathrm{pH}$ 7.4). After $15 \mathrm{~min}$ at $4^{\circ} \mathrm{C}$, the lysate was centrifuged at $200,000 \times \mathrm{g}$ for $15 \mathrm{~min}$ at $4^{\circ} \mathrm{C}$ and the pellet (synaptosomal membranes) was diluted in Tris solution containing $5 \mathrm{~mm}$ EDTA. The synaptosomal membranes were then solubilized with Triton X-100 $(0.2 \% \mathrm{v} / \mathrm{v}$ final concentration $)$ and then centrifuged at $200,000 \times g$ for $15 \mathrm{~min}$ at $4^{\circ} \mathrm{C}$; the supernatant (detergent-soluble membrane fraction) was collected and quantified for 
protein content with Lowry Assay. SDS-PAGE was carried out using 25 $\mu \mathrm{g}$ of detergent-soluble membrane proteins/lane.

Immunoblotting. Proteins were separated by SDS-PAGE, $12.5 \%$ polyacrylamide, and then transferred onto polyvinylidene fluoride membranes. Membranes were washed with phosphate buffer $(20 \mathrm{~mm}$ sodium phosphate buffer, $140 \mathrm{~mm} \mathrm{NaCl}, 5 \% \mathrm{w} / \mathrm{v}$ nonfat dry milk, $5 \%$ v/v Tween20; $\mathrm{pH} 7.4$ ) and incubated $60 \mathrm{~min}$ at $4^{\circ} \mathrm{C}$ with one of the following primary antibodies: rabbit anti-CCR1 (1:1000), mouse anti-CCR3 (1: 1000), mouse anti-CCR5 (1:1000) rabbit anti-CCR1 (1:1000), mouse anti-synaptophysin (anti-Syph; 1:2500), mouse anti-syntaxin-1A (antiStx-1A, 1:5000), mouse anti-glial fibrillary acidic protein (anti-GFAP; 1:1000). After extensive wash, membranes were incubated for $1 \mathrm{~h}$ at $20^{\circ} \mathrm{C}$ with the appropriate horseradish peroxidase-linked secondary antibodies (1:4000) and immunoreactivity was detected by using an enhanced chemiluminescence Western blotting detection system.

Calculations. ANOVA was performed, followed by Dunnett's test or Newman-Keuls multiple-comparisons test as appropriate; direct comparisons were performed by applying Student's $t$ test. Data was considered significant for $p<0.05$ at least.

Drugs. 1-[7,8 $\left.{ }^{3} \mathrm{H}\right] \mathrm{D}$-ASP (specific activity, $16.3 \mathrm{Ci} / \mathrm{mmol}$ ) was from Amersham Radiochemical Center. BAPTA was from Fluka Biochemika. Xestospongin C, Pertussis toxin (PTx) and Ac-RQIKIWFQNRRMKWKKKKKLRRQEAFDAL-OH (ANT-Aip-II) were from Calbiochem. DL-TBOA, 2-[1-(3-dimethylaminopropyl)indol-3-yl]-3-(indol-3-yl)maleimide (GF109203X), and 3-(4-chlorophenyl)1-(1,1-dimethylethyl)1H-pyrazolo[3,4-d]pyrimidin-4-amine (PP2) from Tocris Bioscience. 1-(6[([17 $\beta]$-3-methoxyestra-1,3,5[10]-trien-17-yl)amino]hexyl)- $1 H$-pyrrole-2,5dione (U73122), cis- $\mathrm{N}$-(2-phenylcyclopentyl)-azacyclotridec-1-en-2-amine hydrochloride (MDL-12,330A), $\quad N$-(2-[p-bromocinnamylamino]ethyl)-5isoquinolinesulfonamide hydrochloride (H89), Forskolin, monoclonal anti- $\beta$ tubulin isotype III (clone SDL.3D10) mouse IgG2b, mRANTES, 8-bromoadenosine cAMP (8-Br-cAMP), and anti-GFAP monoclonal mouse were from Sigma-Aldrich; Met-RANTES was purchased from R\&D Systems, and polyclonal anti-CCR1 rabbit IgG (recognizing the amino acid sequence 7-24 of the human CCR1) was from Genetex. Monoclonal anti-CCR3 mouse IgG2a was from Abcam; polyclonal antimGluR1 rabbit IgG and polyclonal anti-mGluR5 rabbit IgG were from Upstate, anti-synaptophysin monoclonal mouse was from Millipore Bioscience Research Reagents, and anti-syntaxin-1A monoclonal mouse IgG was from Synaptic Systems.

\section{Results}

Effect of hRANTES on the spontaneous release of $\left[{ }^{3} \mathrm{H}\right] \mathrm{D}$-ASP from human neocortical synaptosomes

Figure $1 A$ shows that hRANTES, added to the superfusion medium at $1 \mathrm{nM}$, increased the basal release of $\left[{ }^{3} \mathrm{H}\right] \mathrm{D}$-ASP, an unmetabolizable glutamate analog routinely used in release studies as a marker of the endogenous excitatory amino acid transmitter (Rousseau et al., 2005; Raiteri, 2006). Differently from what observed in human fetal neurons (Klein et al., 1999), pre-exposure of human neocortical synaptosomes to a depolarizing stimulus was not required to unveil the effect of hRANTES. The release evoked by hRANTES reached its maximum after $4 \mathrm{~min}$ and remained above basal release at least until the eighth fraction collected. The effect of hRANTES was concentration-dependent; the maximal potentiation of basal release was observed when the protein was applied at $1 \mathrm{~nm}($ Fig. $1 B)$. Of note, the concentrations of hRANTES able to elicit glutamate release are in the range of those found in the CSF of patients during HIV-1 infection (Kelder et al., 1998).

\section{Calcium dependency of the hRANTES-evoked $\left[{ }^{3} \mathrm{H}\right] \mathrm{D}$-ASP release}

The $\left[{ }^{3} \mathrm{H}\right]$ D-ASP release provoked by hRANTES was analyzed for its dependency on $\mathrm{Ca}^{2+}$ ions. Reduction of $\mathrm{Ca}^{2+}$ (from 1.2-0.1 $\mathrm{mM})$ in the superfusion medium and simultaneous addition of

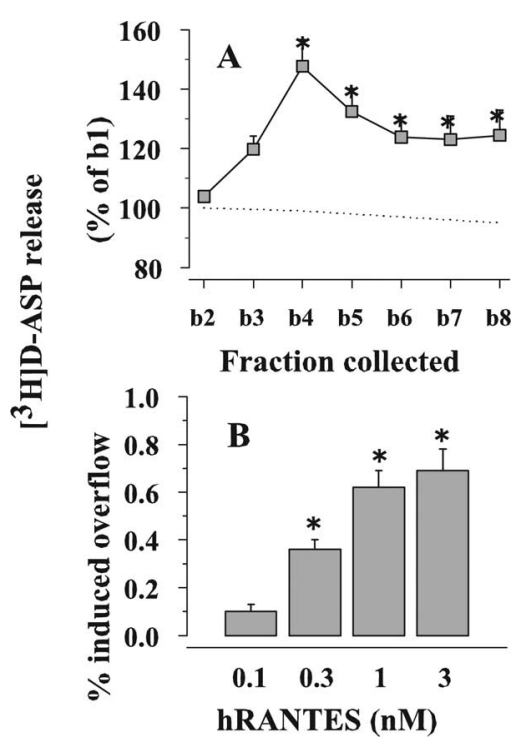

Figure 1. Effects of hRANTES on the $\left[{ }^{3} \mathrm{H}\right] \mathrm{D}-\mathrm{ASP}$ release from human neocortical synaptosomes. $A$, Time course of $\left[^{3} \mathrm{H}\right] \mathrm{D}$-ASP release. Dotted line, Spontaneous release. Gray square, $1 \mathrm{~nm}$ hRANTES-evoked [ $\left.{ }^{3} \mathrm{H}\right] \mathrm{D}-\mathrm{ASP}$ release. Results are expressed as percentages of the first superfusion fraction collected (b1). Data are means \pm SEM of three experiments run in triplicate (3 superfusion chambers for each experimental condition). $\boldsymbol{B}$, Concentration- effect relationship of hRANTES on the release of $\left[{ }^{3} \mathrm{H}\right] \mathrm{D}$-ASP from human neocortical synaptosomes. Results are expressed as percentage of induced overflow. Data are means of four experiments run in triplicate. ${ }^{*} p<0.05$ versus control.

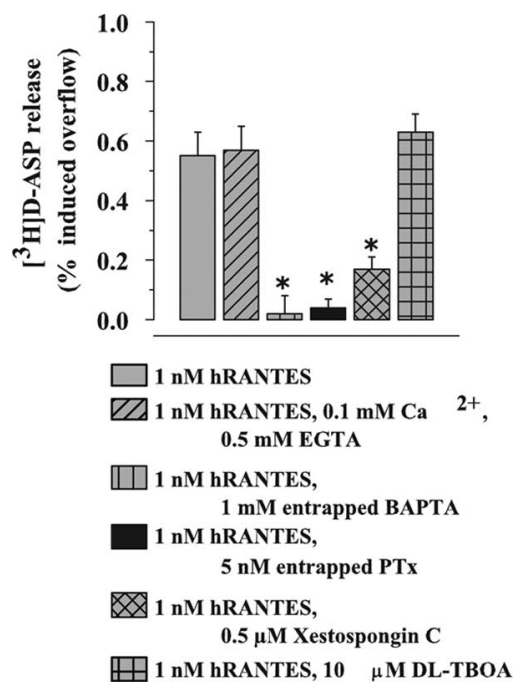

Figure 2. $\mathrm{Ca}^{2+}$ dependency and sensitivity to PTx and DL-TBOA of the hRANTES-induced release of $\left[{ }^{3} \mathrm{H}\right] \mathrm{D}-\mathrm{ASP}$ from human neocortical synaptosomes. Results are expressed as percentage of induced overflow. Data are means \pm SEM of three to seven experiments run in triplicate. ${ }^{*} p<0.05$ versus control.

$500 \mu \mathrm{M}$ EGTA failed to affect the hRANTES-evoked $\left[{ }^{3} \mathrm{H}\right] \mathrm{D}-\mathrm{ASP}$ release (Fig. 2), excluding release by classical external $\mathrm{Ca}^{2+}$ dependent exocytosis. However, entrapping the membraneimpermeant $\mathrm{Ca}^{2+}$ chelator BAPTA into synaptosomes $(1 \mathrm{~mm}$ BAPTA present in the homogenization medium (see Raiteri et al., 2000) abolished the hRANTES effect (Fig. 2), suggesting that the release of $\left[{ }^{3} \mathrm{H}\right] \mathrm{D}$-ASP evoked by the chemokine occurs through an exocytotic-like mechanism triggered by $\mathrm{Ca}^{2+}$ ions originating from internal stores. Omission of external $\mathrm{Ca}^{2+}$ or entrapping of BAPTA did not modify, the spontaneous release of tritium (not shown). 


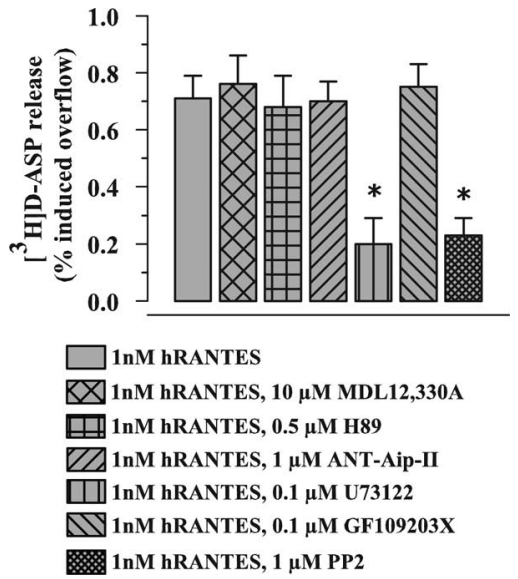

Figure 3. Effects of enzyme inhibitors on the hRANTES-induced release of [ $\left.{ }^{3} \mathrm{H}\right] \mathrm{D}-\mathrm{ASP}$ from human neocortical synaptosomes. Results are expressed as percentage of induced overflow. Data are means \pm SEM of three to five experiments run in triplicate. ${ }^{*} p<0.05$ versus control.

RANTES is known to exert its biological effects via activation of G-protein-coupled receptors. Since some of the chemokineevoked responses were found to be prevented by PTx (Cartier et al., 2005), we verified the sensitivity to PTx of the hRANTESinduced elevation of $\left[{ }^{3} \mathrm{H}\right] \mathrm{D}$-ASP basal release. To avoid prolonged preincubation with the toxin, synaptosomes were staffed with PTx during brain tissue homogenization, as previously described (Longordo et al., 2006). Figure 2 shows that entrapped PTx, unable on its own to modify the spontaneous release (not shown), totally prevented the effect of hRANTES.

Mobilization of intracellular $\mathrm{Ca}^{2+}$ by phosphoinositide metabolites was proposed as one of the intracellular signals activated by RANTES (Baggiolini et al., 1994; Bajetto et al., 2002, Ignatov et al., 2006). The possible involvement of inositoltrisphosphate $\left(\mathrm{IP}_{3}\right)$-mediated mobilization of $\mathrm{Ca}^{2+}$ in the hRANTES-induced release was therefore investigated with xestospongin $\mathrm{C}$, a membrane-permeant $\mathrm{IP}_{3}$ receptor antagonist (Gafni et al., 1997). As shown in Figure 2, xestospongin $\mathrm{C}(0.5 \mu \mathrm{M})$ significantly prevented (by $72.8 \pm 6.3 \%$ ) the hRANTES-evoked release. Finally, the effect of 1 nM hRANTES was totally insensitive to the glutamate transporter blocker DL-TBOA, which excludes exit of $\left[{ }^{3} \mathrm{H}\right] \mathrm{D}$-ASP by carrier-mediated release (Levi and Raiteri, 1993). At the concentration applied, xestospongin $\mathrm{C}$ and DL-TBOA failed to affect, on their own, the spontaneous release of tritium (data not shown).

\section{Transduction mechanisms involved in the hRANTES-evoked} facilitation of $\left[{ }^{3} \mathrm{H}\right]_{\mathrm{D}}$-ASP release

To identify the intraterminal enzymatic pathways participating in the hRANTES potentiation of $\left[{ }^{3} \mathrm{H}\right] \mathrm{D}$-ASP release, we tested a number of enzyme inhibitors: MDL-12,330A, a broad spectrum inhibitor of adenylate cyclase (AC) activity; $\mathrm{H} 89$, a protein kinase A (PKA) inhibitor; Autocamtide-2 related Inhibitory peptide II (ANT-Aip-II), an inhibitor of $\mathrm{Ca}^{2+} /$ calmodulin-dependent protein kinase II; U73122, a phospholipase C (PLC) inhibitor; GF109203X, a protein kinase C (PKC) blocker and PP2, a tyrosine kinase ( $\mathrm{Src}$ ) inhibitor.

As illustrated in Figure 3, the hRANTES (1 nM)-induced release of $\left[{ }^{3} \mathrm{H}\right] \mathrm{D}$-ASP from human neocortical synaptosomes seemed not to depend on the activation of the AC/cAMP/PKApathway, since neither MDL-12,330A nor H89 modified the effect of the chemokine. CaMKII also was not involved, because ANT-Aip-II was ineffective. On the contrary, U73122 largely pre-

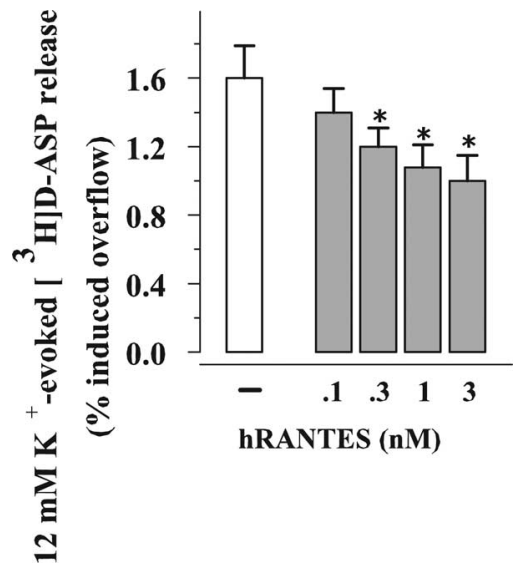

Figure 4. Concentration- effect relationship of hRANTES on the release of $\left[{ }^{3} \mathrm{H}\right] \mathrm{D}-\mathrm{ASP}$ evoked by high $\mathrm{K}^{+}$from human neocortical synaptosomes. Results are expressed as percentage of induced overflow. Data are means \pm SEM from three experiments run in triplicate. ${ }^{*} p<0.05$ versus $12 \mathrm{~mm} \mathrm{~K}^{+}$.

vented the release of $\left[{ }^{3} \mathrm{H}\right] \mathrm{D}$-ASP, consistent with a primary role of PLC; however, the release of $\left[{ }^{3} \mathrm{H}\right] \mathrm{D}-\mathrm{ASP}$ caused by hRANTES was insensitive to GF109203X, suggesting that PKC did not participate in the releasing effect. Finally, the hRANTES effect was significantly prevented by $1 \mu \mathrm{M}$ PP2, consistent with an involvement of Src (Fig. 3). Interestingly, U73122, xestospongin C, and PP2 inhibited to the same extent $(71.41 \pm 5.4 \%, 72.8 \pm 6.3 \%$ and $66.7 \pm 6.7 \%$, respectively) the $1 \mathrm{~nm}$ hRANTES-evoked $\left[{ }^{3} \mathrm{H}\right] \mathrm{D}-$ ASP release (Figs. 2, 3), suggesting that the corresponding targets (PLC, $\mathrm{IP}_{3}$-sensitive $\mathrm{Ca}^{2+}$ pool, and $\mathrm{Src}$ ) constitute the likely pathway involved. At the concentrations used, the enzyme inhibitors were unable, on their own, to modify the spontaneous release of tritium (data not shown).

\section{Effect of hRANTES on the $\mathrm{K}^{+}$-evoked overflow of $\left[{ }^{3} \mathrm{H}\right] \mathrm{D}$-ASP from human neocortical synaptosomes}

Exposure of human neocortical synaptosomes prelabeled with [ ${ }^{3} \mathrm{H}$ ]D-ASP to $12 \mathrm{~mm} \mathrm{KCl}$ has been reported to elicit release by external $\mathrm{Ca}^{2+}$-dependent exocytosis (Raiteri, 2006). Figure 4, shows that the $\mathrm{K}^{+}$-evoked overflow of $\left[{ }^{3} \mathrm{H}\right] \mathrm{D}$-ASP was concentration-dependently (0.1-3 nM) inhibited by hRANTES added contemporary to the depolarizing stimulus. The inhibition was already significant when hRANTES was added at $0.3 \mathrm{~nm}$. Notably, the $\mathrm{K}^{+}$-induced exocytosis was not significantly affected when the chemokine was added immediately before or after the depolarizing stimulus $\left(12 \mathrm{mM} \mathrm{K}^{+}: 1.24 \pm 0.06\right.$; preexposure to $1 \mathrm{~nm}$ hRANTES: $1.18 \pm 0.04$; post-exposure to $1 \mathrm{~nm}$ hRANTES: $1.38 \pm 0.08$ ).

The inhibitory effect of $1 \mathrm{~nm}$ hRANTES was prevented by entrapping PTx into synaptosomes. PTx failed to affect, on its own, the $12 \mathrm{~mm} \mathrm{~K}^{+}$-evoked release of [ $\left.{ }^{3} \mathrm{H}\right] \mathrm{D}$-ASP (Fig. $5 A$ ).

\section{Depolarization-evoked $\left[{ }^{3} \mathrm{H}\right] \mathrm{D}$-ASP release, adenylyl cyclase activity and effects of hRANTES}

To shed light on the transducing mechanisms involved in the RANTES-induced inhibition of glutamate exocytosis, we first investigated the effects of U73122, ANT-Aip-II PP2 and MDL$12,330 \mathrm{~A}$ on the $\mathrm{K}^{+}$-induced release of $\left[{ }^{3} \mathrm{H}\right] \mathrm{D}$-ASP. Selective inhibition of PLC, CaMKII or Src failed to affect the overflow caused by $12 \mathrm{mM} \mathrm{K}^{+}$. On the contrary, the selective AC blocker MDL-12,330A significantly inhibited the depolarization-evoked release of $\left[{ }^{3} \mathrm{H}\right] \mathrm{D}$-ASP, suggesting an involvement of the enzyme 

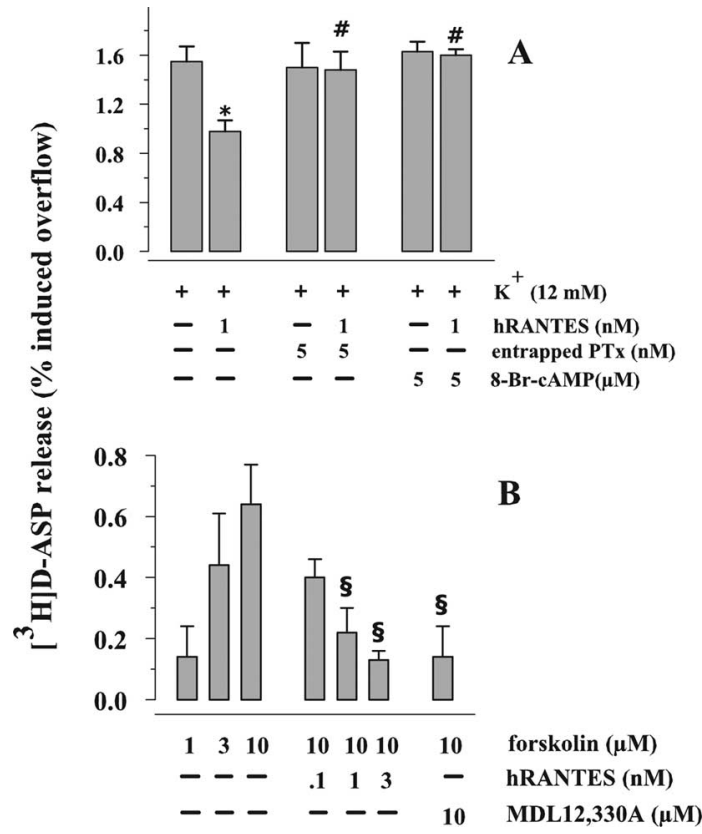

Figure 5. The inhibitory effect of hRANTES on glutamate release from human neocortical synaptosomes involves adenylyl cyclase activity. A, Effects of PTx and 8-Br-cAMP on the $\mathrm{K}^{+}$evoked release of glutamate from human neocortical synaptosomes in absence or in presence of hRANTES. Results are expressed as percentage of induced overflow. Data are means \pm SEM of four experiments run in triplicate. ${ }^{*} p<0.05$ versus control; ${ }^{\#} p<0.05$ versus $12 \mathrm{~mm} \mathrm{~K}^{+} / 1 \mathrm{~nm}$ hRANTES. $\boldsymbol{B}$, Effects of hRANTES and MDL-12,330A on the release of glutamate elicited by forskolin from human neocortical synaptosomes. Results are expressed as percentage of induced overflow. Data are means \pm SEM of three experiments run in triplicate. ${ }^{*} p<0.05$ versus control.

Table 1. Effects of enzyme inhibitors on the $\mathrm{K}^{+}$-evoked release of $\left[{ }^{3} \mathrm{H}\right] \mathrm{D}$-aspartate from human neocortical synaptosomes in the absence or presence of hRANTES

\begin{tabular}{lll}
\hline & {$\left[{ }^{3} \mathrm{H}\right] \mathrm{D}$-aspartate release (\% induced overflow) } \\
\cline { 2 - 3 } & $12 \mathrm{~mm} \mathrm{~K}^{+}$ & $12 \mathrm{~mm} \mathrm{~K}^{+} / 1 \mathrm{~nm}$ hRANTES \\
\hline Control & $1.83 \pm 0.09$ & $1.29 \pm 0.07^{*}$ \\
$0.1 \mu \mathrm{M}$ U73122 & $1.90 \pm 0.25$ & $1.43 \pm 0.12^{*}$ \\
$1 \mu \mathrm{M}$ ANT-Aip-II & $1.92 \pm 0.15$ & $1.46 \pm 0.08^{*}$ \\
$1 \mu \mathrm{M}$ PP2 & $1.78 \pm 0.05$ & $1.32 \pm 0.05^{*}$ \\
$10 \mu \mathrm{M}$ MDL12,330A & $1.39 \pm 0.08^{*}$ & n.d.
\end{tabular}

Synaptosomes were exposed to the chemokine at $t=38 \mathrm{~min}$ of superfusion; enzyme inhibitors were added $8 \mathrm{~min}$ before. Results are expressed as a percentage of induced overflow; data are means \pm SEM of three experiments run in triplicate. ${ }^{*} p<0.05$ versus respective control. n.d., Not determined.

(Table 1). Inhibition of PLC, CaMKII or Src also failed to affect significantly the inhibitory effect of hRANTES (Table 1).

Chemokine receptors are known to couple to different intracellular pathways. In addition to stimulatory effects brought about through $\mathrm{PLC} / \mathrm{IP}_{3}$-dependent $\mathrm{Ca}^{2+}$ mobilization, the chemokine was found to exhibit inhibitory activities mediated by the AC/cAMP/PKA pathway (Myers et al., 1995; Zhao et al., 1998; Blanpain et al., 2002; Amella et al., 2005; Cartier et al., 2005). To clarify this aspect, experiments were carried out with forskolin, a direct activator of AC, in absence of depolarization. As shown in Figure $5 B$, forskolin (1-10 $\mu \mathrm{M})$ concentration-dependently potentiated the spontaneous release of $\left[{ }^{3} \mathrm{H}\right] \mathrm{D}$-ASP. When added at varying concentrations $(0.1-3 \mathrm{nM})$, hRANTES inhibited the release of $\left[{ }^{3} \mathrm{H}\right] \mathrm{D}$-ASP caused by $10 \mu \mathrm{M}$ forskolin. At the maximal concentration applied ( $3 \mathrm{nM})$, hRANTES prevented the release of glutamate caused by forskolin by $>70 \%$. The figure also shows that MDL-12,330A (10 $\mu \mathrm{M})$ depressed to a similar extent the release caused by $10 \mu \mathrm{M}$ forskolin. In line with the proposed
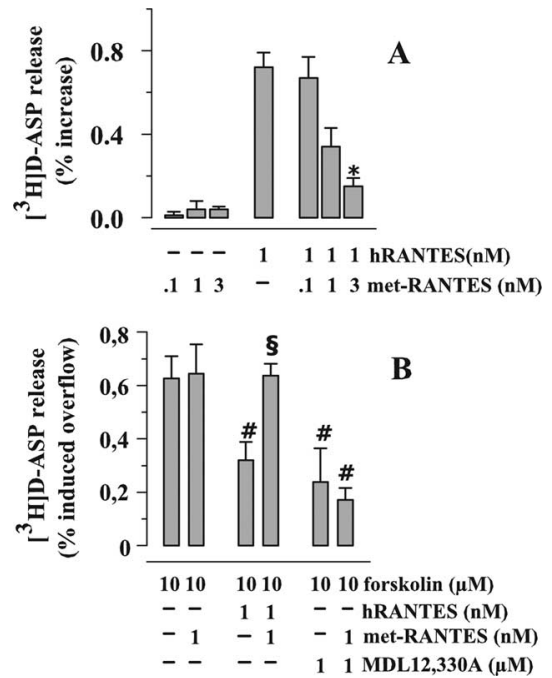

Figure 6. Effects of met-RANTES on the hRANTES-mediated modulation of [ $\left.{ }^{3} \mathrm{H}\right] \mathrm{D}-\mathrm{ASP}$ from human neocortical synaptosomes. $\boldsymbol{A}$, Effects of met-RANTES on the release of [ ${ }^{3} \mathrm{H}$ ]D-ASP induced by hRANTES. Results are expressed as percentage of induced overflow; data are means \pm SEM from four experiments run in triplicate. $\boldsymbol{B}$, Effects of met-RANTES on the hRANTESmediated inhibition of the forskolin-evoked release of $\left[{ }^{3} \mathrm{H}\right] \mathrm{D}$-ASP. Results are expressed as percentage of induced overflow; data are means \pm SEM from five experiments run in triplicate. ${ }^{*} p<0.05$ versus at least 1 nm hRANTES-induced release of tritium; ${ }^{\#} p<0.05$ at least versus 10 $\mu \mathrm{m}$ forskolin; ${ }^{\S} p<0.05$ at least versus $10 \mu \mathrm{m}$ forskolin/ $1 \mathrm{~nm}$ hRANTES.

negative coupling to $\mathrm{AC}$, we found that 8 -Br-cAMP, a stable permeant analog of cAMP was able to abolish the inhibitory effect exerted by hRANTES on the $\left[{ }^{3} \mathrm{H}\right] \mathrm{D}$-ASP overflow (Fig. $5 A$ ). The cAMP analog did not modify on its own the exocytosis of the excitatory amino acid.

\section{Antagonism by met-RANTES of the hRANTES effects on $\left[{ }^{3} \mathrm{H}\right] \mathrm{D}-\mathrm{ASP}$ release}

Met-RANTES is a RANTES derivative which was shown to antagonize the effects of the chemokine in different experimental paradigms (Elsner et al., 1999; Proudfoot et al., 1999). MetRANTES (0.1-1 nM), unable on its own to affect the spontaneous release of $\left[{ }^{3} \mathrm{H}\right] \mathrm{D}$-ASP, prevented the enhancing effect of hRANTES $(1 \mathrm{nM})$ on the release of $\left[{ }^{3} \mathrm{H}\right] \mathrm{D}$-ASP under basal conditions (Fig. 6A). When added alone, met-RANTES (1 nM) failed to affect the release of $\left[{ }^{3} \mathrm{H}\right] \mathrm{D}$-ASP occurring in the presence of 10 $\mu \mathrm{M}$ forskolin (Fig. $6 \mathrm{~B}$ ); however, it abolished the inhibitory effect of $1 \mathrm{~nm}$ hRANTES on this release. As expected, met-RANTES left unchanged the inhibition caused by $10 \mu \mathrm{M}$ MDL-12,330A (Fig. $6 B)$.

\section{Effects of hRANTES on the release of $\left[{ }^{3} \mathrm{H}\right] \mathrm{D}$-ASP from human neocortical slices}

It was important to verify whether the effects seen in synaptosomes, a relatively simplified preparation that facilitates interpretation of results, could be reproduced in brain slices, a more complex, but more intact, preparation. Human neocortical slices were prelabeled with $\left[{ }^{3} \mathrm{H}\right] \mathrm{D}$-ASP and exposed in superfusion to hRANTES. As shown in Table 2, hRANTES ( $1 \mathrm{nM}$ ) increased the spontaneous release of $\left[{ }^{3} \mathrm{H}\right] \mathrm{D}$-ASP. We also investigated the effect of the chemokine on the release evoked by depolarization. Exposure of slices to 30 or $50 \mathrm{mM} \mathrm{KCl}$ caused concentrationdependent overflows of $\left[{ }^{3} \mathrm{H}\right] \mathrm{D}$-ASP. Similarly to what we observed in synaptosomes, $1 \mathrm{~nm}$ hRANTES significantly inhibited the overflow evoked by $30 \mathrm{~mm} \mathrm{~K}^{+}$(by $48.3 \pm 7.1 \%, n=3$ ) or by $50 \mathrm{mM} \mathrm{K}^{+}$(by $\left.39.5 \pm 8.2 \%, n=4\right)$. 
Table 2. Effects of hRANTES and met-RANTES on the spontaneous and the $\mathrm{K}^{+}$evoked release of $\left.{ }^{3} \mathrm{H}\right] \mathrm{D}$-aspartate from human neocortical slices

\begin{tabular}{lcll}
\hline & \multicolumn{3}{l}{$\left[{ }^{3} \mathrm{H}\right] \mathrm{D}$-aspartate release (\% induced overflow) } \\
\cline { 2 - 4 } & Control & 1 nm hRANTES & 1 nm met-RANTES \\
\hline Basal & $0.02 \pm 0.04$ & $0.31 \pm 0.13$ & $0.08 \pm 0.07$ \\
$30 \mathrm{~mm} \mathrm{~K}^{+}$ & $1.24 \pm 0.20$ & $0.64 \pm 0.11^{*}$ & $1.07 \pm 0.11$ \\
$50 \mathrm{~mm} \mathrm{~K}^{+}$ & $10.69 \pm 1.11$ & $6.47 \pm 0.68^{*}$ & $9.22 \pm 0.45$ \\
\hline
\end{tabular}

When studying the effect of hRANTES or met-RANTES on basal release, the compounds were applied starting at $t=$ $70 \mathrm{~min}$ for $5 \mathrm{~min}$. When the effects of hRANTES or met-RANTES on the $\mathrm{K}^{+}$-evoked release were analyzed, the depolarizing stimulus was applied in absence or in presence of the peptides at $t=70 \mathrm{~min}$ for $5 \mathrm{~min}$, then replaced with standard medium. Results are expressed as percent induced overflow; data are means \pm SEM of three to four experiments run in triplicate. ${ }^{*} p<0.05$ versus respective control.

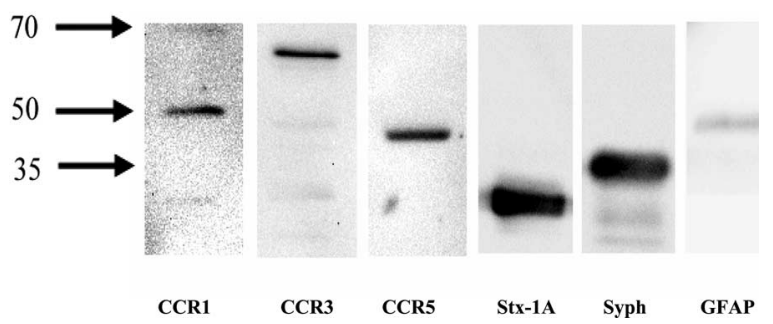

Figure 7. Western blot analysis of CCR1, CCR3 and CCR5 proteins in detergent-soluble synaptosomal membrane fractions. Western blot compares the CCR1, the CCR3, and the CCR5 immunoreactivities in a fraction enriched in human neocortical synaptosomal membranes. Anti-Stx-1A, anti-Syph, and anti-GFAP were used as selective markers of the neuronal and glial components to evaluate the purity of our preparations. Twenty-five micrograms of proteins were applied to the SDS PAGE gel. Protein weights are in kilodaltons. The blot in the figure is representative of four blots from synaptosomal preparations obtained from different patients on different days.

A set of experiments was also performed to investigate the effects of the broad-spectrum CCR antagonist met-RANTES on the basal and the $\mathrm{K}^{+}$-evoked release of $\left[{ }^{3} \mathrm{H}\right] \mathrm{D}$-ASP from human neocortical slices. The antagonist failed to significantly modify basal and depolarization-evoked release (Table 2), suggesting that the endogenous concentrations of RANTES (or of other chemokines acting at CCRs) were insufficient to modify the release of glutamate in our experimental condition.

\section{Human neocortical nerve ending membranes possess CCR1, CCR3, and CCR5 proteins}

RANTES is a promiscuous ligand of the chemokine receptors CCR1, CCR3, and CCR5. Activation of these receptors usually triggers G-protein-coupled PTx-sensitive intracellular pathways, leading to facilitation or inhibition of cellular responses (Zhao et al., 1998; Klein et al., 1999; Boutet et al., 2001; Mueller et al., 2002). Because the effects of hRANTES on $\left[{ }^{3} \mathrm{H}\right] \mathrm{D}$-ASP release are PTx sensitive, CCR1, CCR3, and CCR5 might have mediated the observed effects on basal and depolarization-evoked release. We therefore sought to determine whether CCR1, CCR3, or CCR5 receptor proteins could be identified by Western blot analysis in the detergent-soluble membrane fractions of synaptosomal preparations. To validate the purity of the synaptosomal membrane preparations, we also investigated the presence of selective neuronal (Stx-1A, Syph) and glial (GFAP) markers. Figure 7 shows that selective antibodies recognized immunoreactive protein components with an appropriate apparent mass corresponding to that of the three chemokine receptors. Of note, GFAP immunoreactivity was barely detectable, suggesting that in our synaptosomal preparations, glial contamination was very low. The above findings do not imply that functional receptors for RANTES exist on presynaptic membranes or on other structural components present in synaptosomal preparations. Functional evi-
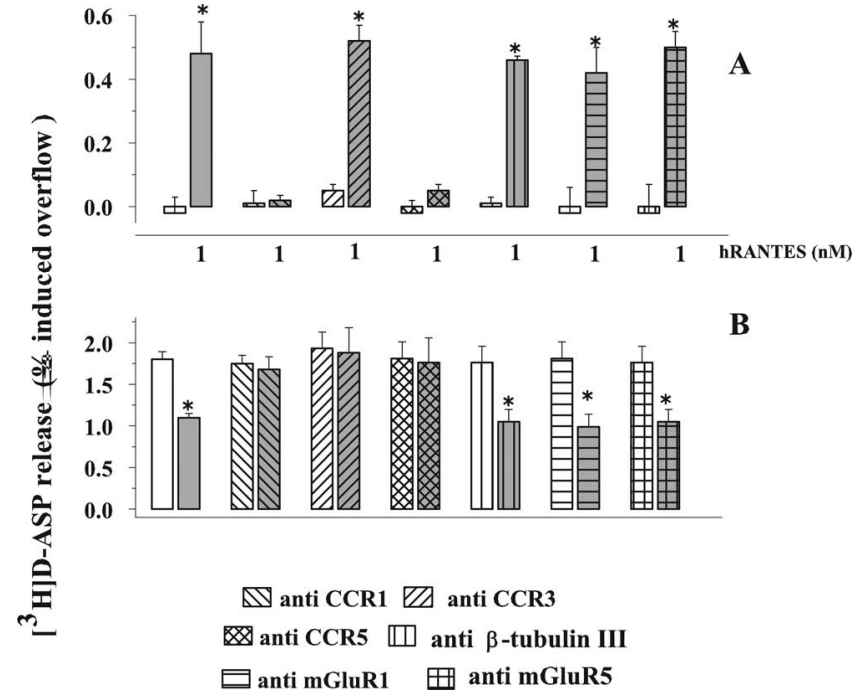

Figure 8. Effects of anti-CCR1, CCR3, and CCR5 antibodies on the hRANTES-induced changes in the spontaneous and the $\mathrm{K}^{+}$-evoked release of [ $\left.{ }^{3} \mathrm{H}\right] \mathrm{D}$-ASP from human neocortical synaptosomes. $\boldsymbol{A}$, Effects on the spontaneous release of $\left[{ }^{3} \mathrm{H}\right] \mathrm{D}$-ASP in absence (white bar) or in presence (gray bar) of hRANTES. $\boldsymbol{B}$, Effects on the release of [ $\left.{ }^{3} \mathrm{H}\right] \mathrm{D}$-ASP evoked by $12 \mathrm{~mm} \mathrm{~K}^{+}$in absence (white bar) or in presence (gray bar) of hRANTES. Results are expressed as percentage of induced overflow. Data are means \pm SEM from 10 experiments run in triplicate. ${ }^{*} p<0.05$ versus respective control; ${ }^{\#} p<0.05$ versus 1 nm hRANTES.

dence was therefore required to show that chemokine receptors indeed mediate the effects of hRANTES on glutamate release.

\section{CCR1, CCR3, and CCR5 antibodies differentially affected the RANTES effects on $\left[{ }^{3} \mathrm{H}\right]_{\mathrm{D}}$-ASP release}

It has been shown that antibodies raised against chemokine receptors can prevent cellular responses by favoring receptor internalization (Wells et al., 2006) and/or by mimicking selective chemokine receptor antagonists (Heath et al., 1997). We therefore investigated whether antibodies raised against the extracellular domain of the chemokine receptors potentially targeted by RANTES (CCR1, CCR3, and CCR5) would interfere with the hRANTES-releasing effects here characterized. To exclude possible artifacts caused by a specific binding of antibodies onto synaptosomal membranes, we also tested antibodies raised against the cytosolic protein $\beta$-tubulin III, as well as antibodies raised against the metabotropic glutamate receptor 1 or 5 (mGluR1 or mGluR5, respectively). We focused on these receptors because preliminary results (V. Musante, F. Longordo, and A. Pittaluga, unpublished observations) had shown that the selective mGluR1/5 receptor agonist 3,5-DHPG facilitated the $\mathrm{K}^{+}$-evoked release of glutamate from human neocortical synaptosomes, suggesting the existence of presynaptic mGluR $1 / 5$ receptors in this synaptosomal preparation.

Figure $8 \mathrm{~A}$ shows that pretreatment of synaptosomes with anti-CCR 1 or with anti-CCR 5 antibodies almost totally prevented the effect of $1 \mathrm{nM}$ hRANTES on the spontaneous release of $\left[{ }^{3} \mathrm{H}\right] \mathrm{D}$-ASP, whereas preexposure to antibodies raised against CCR 3 (or control antibodies, i.e., anti- $\beta$-tubulin III, antimGluR1 or anti-mGluR5 antibodies) left unchanged the effect of the chemokine. Antibodies failed to affect, on their own, the spontaneous release of $\left[{ }^{3} \mathrm{H}\right] \mathrm{D}$-ASP (control: $0.03 \pm 0.07$; antiCCR1: $0.06 \pm 0.08$; anti-CCR3: $0.11 \pm 0.08$; anti-CCR5: $0.02 \pm$ 0.05; anti- $\beta$-tubulin 3: $0.09 \pm 0.08$; anti-mGluR1: $0.10 \pm 0.09$; anti-CCR1: $0.06 \pm 0.08$; anti-mGluR5: $0.03 \pm 0.04$ ).

We finally investigated the effects of CCR1, CCR3, and CCR5 


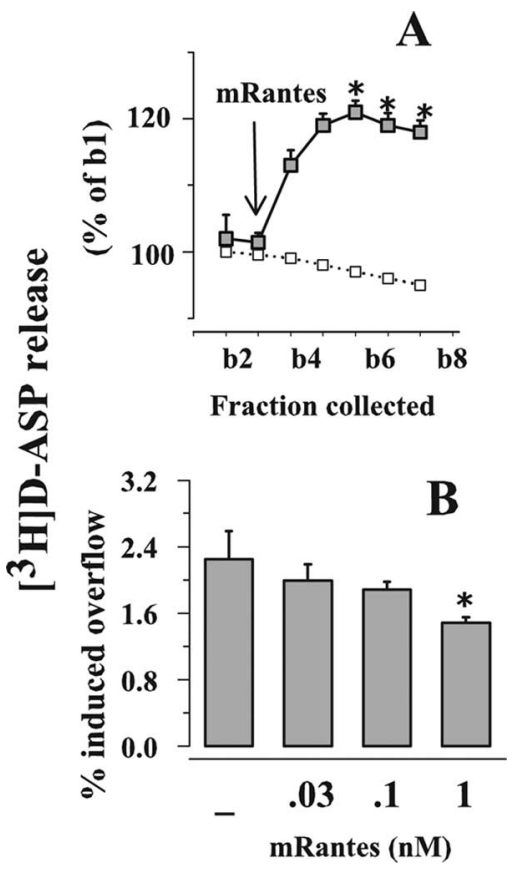

Figure 9. Effects of mRANTES on the release of glutamate from mouse cortical synaptosomes. $\boldsymbol{A}$, Effect of mRANTES ( $1 \mathrm{~nm}$ ) on the spontaneous release of $\left[{ }^{3} \mathrm{H}\right] \mathrm{D}-\mathrm{ASP}$. Synaptosomes were exposed to $1 \mathrm{~nm}$ mRANTES at the end of the first fraction collected (b1). Results are expressed as percentages of the first superfusion fraction collected (b1). Data are means \pm SEM of three experiments run in triplicate. $\boldsymbol{B}$, Effects of mRANTES (0.1-1 nm) on the $12 \mathrm{~mm} \mathrm{~K}^{+}$evoked release of $\left[{ }^{3} \mathrm{H}\right] \mathrm{D}-\mathrm{ASP}$. Results are expressed as percentage of induced overflow. Data are means \pm SEM from three experiments run in triplicate. ${ }^{*} p<0.05$ versus $12 \mathrm{~mm} \mathrm{~K}^{+}$.

antibodies on the inhibition by hRANTES of the overflow of $\left[{ }^{3} \mathrm{H}\right] \mathrm{D}$-ASP elicited by depolarization with high $\mathrm{K}^{+}$. As shown in Figure $8 B$, pretreatment with the three antibodies abolished completely the effect of $1 \mathrm{~nm}$ hRANTES, whereas control antibodies were ineffective; the chemokine maintained its activity in synaptosomes pretreated with anti- $\beta$-tubulin III antibodies. The figure also shows that the antibodies failed to affect, on their own, the release of $\left[{ }^{3} \mathrm{H}\right] \mathrm{D}$-ASP evoked by $12 \mathrm{mM} \mathrm{K}^{+}$from human neocortical synaptosomes.

Effects of RANTES on the spontaneous and on the $\mathrm{K}^{+}$-evoked initiation of $\left[{ }^{3} \mathrm{H}\right] \mathrm{D}$-ASP release from mouse cortical synaptosomes

Experiments were performed to ascertain whether the observed effects of hRANTES in human neocortex could be reproduced in an experimental animal model. To this aim, we studied the effects of mRANTES on the spontaneous and the $12 \mathrm{mM} \mathrm{K}^{+}$-evoked release of $\left[{ }^{3} \mathrm{H}\right] \mathrm{D}$-ASP from mouse cortical synaptosomes. As illustrated in Figure 9, mRANTES, added to the superfusion medium at $1 \mathrm{~nm}$ and significantly potentiated the spontaneous release of $\left[{ }^{3} \mathrm{H}\right]$ D-ASP (Fig. 9A); moreover, the chemokine strongly inhibited the $12 \mathrm{mM} \mathrm{K}^{+}$-evoked overflow of $\left[{ }^{3} \mathrm{H}\right] \mathrm{D}$-ASP when applied at 0.1-1.0 nM (Fig. 9B).

\section{Discussion}

This is the first functional study of the effects of the chemokine RANTES in human brain. The work was focused on the modulation by RANTES of glutamate release from nerve endings of human neocortex isolated from fresh samples removed during neurosurgery to reach deeply located tumors. The most relevant finding is that RANTES can modulate bidirectionally the release of glutamate by acting at PTx-sensitive receptors located on glutamatergic nerve endings.

The presynaptic nature of the hRANTES effects is strongly suggested by the characteristics of the technique used to study release. Indeed, the superfusion of synaptosome monolayers has long been considered an approach particularly appropriate to investigate presynaptic receptors located on axon terminals and regulating neurotransmitter release (Raiteri and Raiteri, 2000) and their activation by selective ligands. In particular, the possibility that RANTES-induced releasing effects could be due to indirect events caused by aspartate released from one synaptosome acting at neighboring synaptosomes seems unlikely. Actually, as shown in several reports from our and other laboratories, the continuous up-down superfusion of a monolayer of synaptosomes causes immediate removal of any compound released, before it can activate targets located on neighboring nerve terminals (Raiteri and Raiteri, 2000). Thus, the effects of RANTES can only reasonably be attributed to a direct action of the chemokine at chemokine receptors located presynaptically on glutamatergic terminals.

Our results unveil a dual role of RANTES on central glutamate transmission: the chemokine, under basal conditions, can elicit an internal $\mathrm{Ca}^{2+}$-dependent, exocytotic-like release of glutamate. On the other hand, RANTES can inhibit glutamate exocytosis evoked by depolarization. These effects depend on the activation of distinct PTx-sensitive receptor-mediated pathways. The RANTES effects were also observed in neocortical slices, where the intimate connections between neurons and glial cells are maintained.

The release of glutamate induced by RANTES under basal conditions depended on PLC activation and mobilization of $\mathrm{Ca}^{2+}$ from $\mathrm{IP}_{3}$-sensitive intraterminal stores. As previously shown in isolated human neocortex noradrenergic nerve terminals, activation of glutamate metabotropic 1 receptors also involved PKC and Src (Longordo et al., 2006). In contrast, Src, but not PKC, seems to participate in the RANTES effect. Of note, PLC activation, $\mathrm{Ca}^{2+}$ mobilization from $\mathrm{IP}_{3}$-sensitive stores and Srcmediated phosphorylation contributed equally (Figs. 2, 3), suggesting that these events occur simultaneously. The contemporary involvement of PLC and Src could be explained by assuming that RANTES induces the dissociation of G-protein heterotrimer into $\alpha$ and $\beta \gamma$ subunits. If this is the case, $\alpha$ subunits could activate Src (Cartier et al. 2005) to trigger a phosphorylative cascade of events that contributes, together with the $\beta \gamma$-evoked PLC/IP3induced $\mathrm{Ca}^{2+}$ mobilization, to glutamate release.

The second relevant finding of this study is that hRANTES was able to inhibit the exocytosis of glutamate evoked by moderate $\mathrm{K}^{+}$depolarization of human neocortical nerve endings. This finding was unexpected. In fact, if RANTES can activate chemokine receptors coupled to mobilization of internal $\mathrm{Ca}^{2+}$ from $\mathrm{IP}_{3}$-sensitive stores, the depolarization-evoked exocytosis of glutamate should be potentiated. Meanwhile it is worth reminding that some receptors, like the serotonin $5-\mathrm{HT}_{2}$ receptors, were reported to mediate inhibition of the depolarization-evoked glutamate exocytosis, despite their positive coupling to the phosphoinositide pathway (Wang et al., 2006).

On the other hand, the inhibition of the $\mathrm{K}^{+}$-evoked release of glutamate brought about by hRANTES was mimicked by an inhibitor of AC and reverted by 8-Br-cAMP, suggesting that the chemokine could have inhibited glutamate exocytosis through a blockade of terminal AC. Phosphorylative processes mediated by AC were previously shown to play a role in glutamate exocytosis from rat (Wang and Sihra, 2003) and mouse (Grilli et al., 2004) 
cortical glutamatergic synaptosomes. Similarly, the external $\mathrm{Ca}^{2+}$-dependent exocytosis of glutamate evoked by high $\mathrm{K}^{+}$ from human neocortical glutamatergic terminals may depend on similar events, as suggested by the findings that blockade of AC inhibited in part the $\mathrm{K}^{+}$-induced glutamate release, while AC activation by forskolin caused release of the amino acid.

Most interestingly, hRANTES not only inhibited the $\mathrm{K}^{+}$evoked overflow of glutamate to the same extent as the adenylyl cyclase inhibitor MDL-12,330A, but it also mimicked this enzyme blocker by inhibiting the release of the excitatory amino acid occurring in the presence of forskolin. The inhibitory effect of hRANTES on the depolarization-evoked glutamate overflow was PTx-sensitive, compatible with the idea that the chemokine acted through G-protein-coupled receptors negatively linked to AC. As mentioned above, the chemokine receptors preferentially targeted by RANTES are CCR1, CCR3 and CCR5, which can mediate a number of PTx-sensitive effects. Based on our Western blot experiments, the proteins of the three chemokine receptors are present in our synaptosomal preparations and may be expressed on the plasma membranes of nerve terminals. Although synaptosomal preparations contain many families of nerve endings, glutamatergic nerve terminals in the mammalian cerebrocortex were found to be extremely abundant ( $\sim 80 \%$ of the total) (Millán et al., 2003); therefore chemokine receptors are likely to exist on glutamatergic terminals. Nonetheless, convincing evidence that the chemokine receptors are present on human glutamatergic terminals could only come from experiments in which one function of these terminals, i.e., glutamate release, was examined.

The effects of RANTES on the release of glutamate were then challenged against met-RANTES, a chemokine receptor antagonist, unable, however, to discriminate among CCR1, CCR3 and CCR5 subtypes (Proudfoot et al., 1999). As clearly illustrated in Figure 5, met-RANTES was able to antagonize both the hRANTES-induced augmentation of basal glutamate release and the inhibition of glutamate exocytosis brought about by the chemokine. These results indicate that CCR1, CCR3 and CCR5 alone or in combination are localized on glutamate-releasing nerve endings in human neocortex. The coupling of the receptors to different transducing pathways, $\mathrm{PLC} / \mathrm{IP}_{3}$ under basal conditions and adenylyl cyclase/PKA under depolarizing conditions, may have a number of explanations. For instance, it was shown that the chemokine receptors exist as homodimers or heterodimers and that the dimer composition can direct the coupling to different transducing pathways (Mellado et al., 2001; El-Asmar et al., 2005; Springael et al., 2005).

Trying to circumvent the problem of the lack of selective chemokine receptor antagonists, we used antibodies raised against the extracellular domains of chemokine receptors (Heath et al., 1997; Wells et al., 2006) as potential antagonists. Pretreatment with CCR1 or CCR5 antibodies prevented both the effects of hRANTES on basal and $\mathrm{K}^{+}$-evoked release, while pretreatment with CCR3 antibodies only abolished the RANTES inhibition of the depolarization-evoked glutamate overflow. The loss of function of RANTES in the antibodies pretreated synaptosomes gives further support to the existence of presynaptic CCRs in human neocortical glutamatergic nerve terminals. Whether these receptors localize on the same terminals or on different subpopulations of glutamatergic terminals cannot be predicted, although functional results seem to favor the hypothesis of colocalization. The differential block of the RANTES effects by CCR3 antibodies can only be matter of speculation. For instance, oligomerization processes unveiled by the depolarizing stimuli may favor a CCR1/
CCR5-dependent activation of presynaptic CCR3, colocalized with CCR1/CCR5 complex.

To conclude, we here show for the first time that glutamatergic nerve endings in human neocortex are endowed with chemokine receptor subtypes (CCR1, CCR3 and CCR5) whose activation by RANTES can differentially modulate glutamate release. Several authors reported the ability of RANTES to mobilize $\mathrm{Ca}^{2+}$ ions in cultured neurons (Bolin et al., 1998; Meucci et al., 1998; Boutet et al., 2001; Oh et al., 2001; Gillard et al., 2002; Mueller et al., 2002; Watson et al., 2005; Ignatov et al., 2006), an observation consistent with release of glutamate evoked by RANTES. The facilitation by RANTES of glutamate release may, by one side, explain the pathogenic effects that the chemokine can produce under some pathological conditions associated with neuroinflammation (i.e., HIV-1 infection, multiple sclerosis), including the regulation of T-cell chemotactic migration in CNS. Actually, the glutamate released by RANTES may contribute to the recruitment, the transmigration and the penetration in the CNS of T-lymphocytes bearing glutamate receptors, an event proposed to occur in defined phases of multiple sclerosis (Ganor et al., 2003; Sarchielli et al., 2007). On the other hand, RANTES has been reported to protect neurons from neurotoxic insults mediated by the HIV-1 viral protein gp120 (Kaul and Lipton, 1999; Kaul et al., 2007). Since the gp120-induced neuronal death depends on glutamate-dependent excitotoxic events, the hRANTES-mediated inhibition of the evoked glutamate release may be considered as one of the mechanisms underlying neuroprotection. Of particular interest is the finding that, while receptors of CCR 1 and CCR5 subtypes can both mediate stimulation and inhibition of release, CCR3 appear to selectively mediate inhibition of glutamate efflux, suggesting that a selective CCR3 agonist may exhibit neuroprotective activities.

One may wonder if the present data have physiological or pathological implications. As RANTES can hardly be detected in the CSF of normal subjects, the effects on glutamate release elicited by exogenous RANTES may better reflect a pathological condition. On the other hand, the results obtained with mouse brain, very similar to those with human brain, suggest that the presence of tumors does not cause major changes in the functional response of CCRs here considered.

It is known that RANTES, normally present extracellularly in minimal amounts, is released by activated glial cells (Thellung et al., 2007) and the glial production/release of the chemokine can be controlled through group III metabotropic glutamate receptors (Besong et al., 2002). These observations, together with the findings reported here enrich the scenario of the neuron-glia interactions by adding the possibility that glial RANTES modulates glutamate release from nerve endings while glutamate controls glial production/release of RANTES. Since the neuron-glia interaction seems crucial to neuronal plasticity as well as to neurodegenerative processes, the knowledge of the mechanisms underlying the RANTES-glutamate system could be helpful in developing new therapeutic approaches.

\section{References}

Alvarez Losada S, Cantó-Nogués C, Muñoz-Fernández MA (2002) A new possible mechanism of human immunodeficiency virus type 1 infection of neural cells. Neurobiol Dis 11:469-478.

Amella CA, Sherry B, Shepp DH, Schmidtmayerova H (2005) Macrophage inflammatory protein lalpha inhibits postentry steps of human immunodeficiency virus type 1 infection via suppression of intracellular cyclic AMP. J Virol 79:5625-5631.

Baggiolini M, Dewald B, Moser B (1994) Interleukin-8 and related chemotactic cytokines-CXC and CC chemokines. Adv Immunol 55:97-179. 
Bajetto A, Bonavia R, Barbero S, Schettini G (2002) Characterization of chemokines and their receptors in the central nervous system: physiopathological implications. J Neurochem 82:1311-1329.

Besong G, Battaglia G, D’Onofrio M, Di Marco R, Ngomba RT, Storto M, Castiglione M, Mangano K, Busceti CL, Nicoletti FR, Bacon K, Tusche M, Valenti O, Conn PJ, Bruno V, Nicoletti F (2002) Activation of group III metabotropic glutamate receptors inhibits the production of RANTES in glial cell cultures. J Neurosci 22:5403-5411.

Blanpain C, Vanderwinden JM, Cihak J, Wittamer V, Le Poul E, Issafras H, Stangassinger M, Vassart G, Marullo S, Schlndorff D, Parmentier M, Mack M (2002) Multiple active states and oligomerization of CCR5 revealed by functional properties of monoclonal antibodies. Mol Biol Cell 13:723-737.

Bolin LM, Murray R, Lukacs NW, Strieter RM, Kunkel SL, Schall TJ, Bacon KB (1998) Primary sensory neurons migrate in response to the chemokine RANTES. J Neuroimmunol 81:49-57.

Boutet A, Salim H, Leclerc P, Tardieu M (2001) Cellular expression of functional chemokine receptor CCR5 and CXCR4 in human embryonic neurons. Neurosci Lett 311:105-108.

Bradford MM (1976) A rapid and sensitive method for the quantitation of microgram quantities of protein utilizing the principle of protein-dye binding. Anal Biochem 72:248-254.

Cartier L, Hartley O, Dubois-Dauphin M, Krause KH (2005) Chemokine receptors in the central nervous system: role in brain inflammation and neurodegenerative diseases. Brain Res Brain Res Rev 48:16-42.

Cho C, Miller RJ (2002) Chemokine receptors and neural function. J Neurovirol 8:573-584.

Dunkley PR, Jarvie PE, Heath JW, Kidd GJ, Rostas JA (1986) A rapid method for isolation of synaptosomes on Percoll gradients. Brain Res 372:115-129.

El-Asmar L, Springael JY, Ballet S, Andrieu EU, Vassart G, Parmentier M (2005) Evidence for negative binding cooperativity within CCR5-CCR2b heterodimers. Mol Pharmacol 67:460-469.

Elsner J, Petering H, Kimmig D, Wells TN, Proudfoot AE, Kapp A (1999) The CC chemokine receptor antagonist met-RANTES inhibits eosinophil effector functions. Int Arch Allergy Immunol 118:462-465.

Gafni J, Munsch JA, Lam TH, Catlin MC, Costa LG, Molinski TF, Pessah IN (1997) Xestospongins: potent membrane permeable blockers of the inositol 1,4,5-trisphosphate receptor. Neuron 19:723-733.

Ganor Y, Besser M, Ben-Zakay N, Unger T, Levite M (2003) Human T cells express a functional ionotropic glutamate receptor GluR3, and glutamate by itself triggers integrin-mediated adhesion to laminin and fibronectin and chemotactic migration. J Immunol 170:4362-4372.

Gillard SE, Lu M, Mastracci RM, Miller RJ (2002) Expression of functional chemokine receptors by rat cerebellar neurons. J Neuroimmunol 124:16-28.

Grilli M, Raiteri L, Pittaluga A (2004) Somatostatin inhibits glutamate release from mouse cerebrocortical nerve endings through presynaptic sst2 receptors linked to the adenylyl cyclase-protein kinase A pathway. Neuropharmacology 46:388-396.

Heath H, Qin S, Rao P, Wu L, LaRosa G, Kassam N, Ponath PD, Mackay CR (1997) Chemokine receptor usage by human eosinophils. The importance of CCR3 demonstrated using an antagonistic monoclonal antibody. J Clin Invest 99:178-184.

Hegg CC, Hu S, Peterson PK, Thayer SA (2000) Beta-chemokines and human immunodeficiency virus type-1 proteins evoke intracellular calcium increases in human microglia. Neuroscience 98:191-199.

Iarlori C, Reale M, Lugaresi A, De Luca G, Bonanni L, Di Iorio A, Feliciani C, Conti P, Gambi D (2000) RANTES production and expression is reduced in relapsing-remitting multiple sclerosis patients treated with interferon-beta-1b. J Neuroimmunol 107:100-107.

Ignatov A, Robert J, Gregory-Evans C, Schaller HC (2006) RANTES stimulates $\mathrm{Ca}^{2+}$ mobilization and inositol trisphosphate $\left(\mathrm{IP}_{3}\right)$ formation in cells transfected with $\mathrm{G}$ protein-coupled receptor 75 . Br J Pharmacol 149:490-497.

Karpus WJ, Ransohoff RM (1998) Chemokine regulation of experimental autoimmune encephalomyelitis: temporal and spatial expression patterns govern disease pathogenesis. J Immunol 161:2667-2671.

Kaul M, Lipton SA (1999) Chemokines and activated macrophages in HIV gp120-induced neuronal apoptosis. Proc Natl Acad Sci U S A 96:8212-8216.

Kaul M, Ma Q, Medders KE, Desai MK, Lipton SA (2007) HIV-1 corecep- tors CCR5 and CXCR4 both mediate neuronal cell death but CCR5 paradoxically can also contribute to protection. Cell Death Differ 14:296-305.

Kelder W, McArthur JC, Nance-Sproson T, McClernon D, Griffin DE (1998) Beta-chemokines MCP-1 and RANTES are selectively increased in cerebrospinal fluid of patients with human immunodeficiency virusassociated dementia. Ann Neurol 44:831-835.

Klein RS, Williams KC, Alvarez-Hernandez X, Westmoreland S, Force T, Lackner AA, Luster AD (1999) Chemokine receptor expression and signaling in macaque and human fetal neurons and astrocytes: implications for the neuropathogenesis of AIDS. J Immunol 163:1636-1646.

Kolb SA, Sporer B, Lahrtz F, Koedel U, Pfister HW, Fontana A (1999) Identification of a $\mathrm{T}$ cell chemotactic factor in the cerebrospinal fluid of HIV1 -infected individuals as interferon-gamma inducible protein 10. J Neuroimmunol 93:172-181.

Levi G, Raiteri M (1993) Carrier-mediated release of neurotransmitters. Trends Neurosci 16:415-419.

Longordo F, Feligioni M, Chiaramonte G, Sbaffi PF, Raiteri M, Pittaluga A (2006) The human immunodeficiency virus-1 protein transactivator of transcription up-regulates $\mathrm{N}$-methyl-D-aspartate receptor function by acting at metabotropic glutamate receptor 1 receptors coexisting on human and rat brain noradrenergic neurones. J Pharmacol Exp Ther 317:1097-1105.

McManus CM, Weidenheim K, Woodman SE, Nunez J, Hesselgesser J, Nath A, Berman JW (2000) Chemokine and chemokine-receptor expression in human glial elements: induction by the HIV protein, Tat, and chemokine autoregulation. Am J Pathol 156:1441-1453.

Mellado M, Rodríguez-Frade JM, Vila-Coro AJ, Fernández S, Martín de Ana A, Jones DR, Torán JL, Martínez-A C (2001) Chemokine receptor homo- or heterodimerization activates distinct signaling pathways. EMBO J 20:2497-2507.

Meucci O, Fatatis A, Simen AA, Bushell TJ, Gray PW, Miller RJ (1998) Chemokines regulate hippocampal neuronal signaling and gp120 neurotoxicity. Proc Natl Acad Sci U S A 95:14500-14505.

Millán C, Torres M, Sánchez-Prieto J (2003) Co-activation of PKA and PKC in cerebrocortical nerve terminals synergistically facilitates glutamate release. J Neurochem 87:1101-1111.

Mueller A, Mahmoud NG, Goedecke MC, McKeating JA, Strange PG (2002) Pharmacological characterization of the chemokine receptor, CCR5. Br J Pharmacol 135:1033-1043.

Myers SJ, Wong LM, Charo IF (1995) Signal transduction and ligand specificity of the human monocyte chemoattractant protein- 1 receptor in transfected embryonic kidney cells. J Biol Chem 270:5786-5792.

Oh SB, Tran PB, Gillard SE, Hurley RW, Hammond DL, Miller RJ (2001) Chemokines and glycoprotein 120 produce pain hypersensitivity by directly exciting primary nociceptive neurons. J Neurosci 21:5027-5035.

Oh SB, Endoh T, Simen AA, Ren D, Miller RJ (2002) Regulation of calcium currents by chemokines and their receptors. J Neuroimmunol 123:66-75.

Proudfoot AE, Buser R, Borlat F, Alouani S, Soler D, Offord RE, Schröder JM, Power CA, Wells TN (1999) Amino-terminally modified RANTES analogues demonstrate differential effects on RANTES receptors. J Biol Chem 274:32478-32485.

Raiteri L, Raiteri M (2000) Synaptosomes still viable after 25 years of superfusion Neurochem Res 25:1265-1274.

Raiteri M (2006) Functional pharmacology in human brain. Pharmacol Rev 58:162-193.

Raiteri M, Sala R, Fassio A, Rossetto O, Bonanno G (2000) Entrapping of impermeant probes of different size into nonpermeabilized synaptosomes as a method to study presynaptic mechanisms. J Neurochem 74:423-431.

Ransohoff RM, Hamilton TA, Tani M, Stoler MH, Shick HE, Major JA, Estes ML, Thomas DM, Tuohy VK (1993) Astrocyte expression of mRNA encoding cytokines IP-10 and JE/MCP-1 in experimental autoimmune encephalomyelitis. FASEB J 7:592-600.

Rousseau SJ, Jones IW, Pullar IA, Wonnacott S (2005) Presynaptic $\alpha 7$ and non- $\alpha 7$ nicotinic acetylcholine receptors modulate $\left[{ }^{3} \mathrm{H}\right] \mathrm{D}$-aspartate release from rat frontal cortex in vitro. Neuropharmacology 49:59-72.

Sarchielli P, Di Filippo M, Candeliere A, Chiasserini D, Mattioni A, Tenaglia S, Bonucci M, Calabresi P (2007) Expression of ionotropic glutamate receptor GLUR3 and effects of glutamate on MBP- and MOG-specific lymphocyte activation and chemotactic migration in multiple sclerosis patients. J Neuroimmunol 188:146-158. 
Sørensen TL, Tani M, Jensen J, Pierce V, Lucchinetti C, Folcik VA, Qin S, Rottman J, Sellebjerg F, Strieter RM, Frederiksen JL, Ransohoff RM (1999) Expression of specific chemokines and chemokine receptors in the central nervous system of multiple sclerosis patients. J Clin Invest 103:807-815.

Springael JY, Urizar E, Parmentier M (2005) Dimerization of chemokine receptors and its functional consequences. Cytokine Growth Factor Rev $16: 611-623$.

Thellung S, Corsaro A, Villa V, Venezia V, Nizzari M, Bisaglia M, Russo C, Schettini G, Aceto A, Florio T (2007) Amino-terminally truncated prion protein PrP90-231 induces microglial activation in vitro. Ann N Y Acad Sci 1096:258-270.

Ubogu EE, Cossoy MB, Ransohoff RM (2006) The expression and function of chemokines involved in CNS inflammation. Trends Pharmacol Sci 27:48-55.

van der Meer P, Ulrich AM, Gonźalez-ScaranoF, Lavi E (2000) Immunohistochemical analysis of CCR2, CCR3, CCR5, and CXCR4 in the human brain: potential mechanisms for HIV dementia. Exp Mol Pathol 69:192-201.

Wang SJ, Sihra TS (2003) Opposing facilitatory and inhibitory modulation of glutamate release elicited by cAMP production in cerebrocortical nerve terminals (synaptosomes). Neuropharmacology 44:686-697.

Wang SJ, Wang KY, Wang WC, Sihra TS (2006) Unexpected inhibitory regulation of glutamate release from rat cerebrocortical nerve terminals by presynaptic 5-hydroxytryptamine-2A receptors. J Neurosci Res $84: 1528-1542$.

Watson C, Jenkinson S, Kazmierski W, Kenakin T (2005) The CCR5 receptor-based mechanism of action of 873140 , a potent allosteric noncompetitive HIV entry inhibitor. Mol Pharmacol 67:1268-1282.

Wells TN, Power CA, Shaw JP, Proudfoot AE (2006) Chemokine blockerstherapeutics in the making? Trends Pharmacol Sci 27:41-47.

Zhao J, Ma L, Wu YL, Wang P, Hu W, Pei G (1998) Chemokine receptor CCR5 functionally couples to inhibitory $\mathrm{G}$ proteins and undergoes desensitization. J Cell Biochem 71:36-45. 